\title{
BM] open Concomitant chronic pulmonary diseases and their association with hospital outcomes in patients with anaphylaxis and other allergic conditions: a cohort study
}

\author{
Zuber D Mulla, ${ }^{1,2}$ F Estelle R Simons ${ }^{3}$
}

To cite: Mulla ZD, Simons FER. Concomitant chronic pulmonary diseases and their association with hospital outcomes in patients with anaphylaxis and other allergic conditions: a cohort study. BMJ Open 2013;3:e003197.

doi:10.1136/bmjopen-2013003197

- Prepublication history for this paper is available online. To view these files please visit the journal online (http://dx.doi.org/10.1136/ bmjopen-2013-003197).

Received 9 May 2013 Revised 14 June 2013 Accepted 26 June 2013

${ }^{1}$ Department of Obstetrics and Gynecology, Paul

L. Foster School of Medicine, Texas Tech University Health Sciences Center, El Paso, Texas, USA

${ }^{2}$ University of Texas School of Public Health at Houston, El Paso Regional Campus, El Paso, Texas, USA ${ }^{3}$ Department of Pediatrics and Child Health and Department of Immunology, Faculty of Medicine, University of Manitoba, Winnipeg, Manitoba, Canada

Correspondence to Dr Zuber D Mulla; zuber.mulla@ttuhsc.edu

\section{ABSTRACT}

Objectives: To determine if chronic pulmonary diseases adversely impact selected outcomes in hospitalised patients who have various allergic conditions including anaphylaxis.

Design: A population-based cohort study.

Participants: A statewide hospital inpatient discharge database from Texas, USA, covering the years 20042007 was analysed. Patients with anaphylaxis and other allergic conditions were identified using the International Classification of Diseases, Ninth Revision, Clinical Modification codes. Within each group of patients (the overall group with various selected allergic conditions and the subgroup with anaphylaxis), the exposure variables were 11 chronic pulmonary diseases including asthma, chronic obstructive pulmonary disease (COPD) and cystic fibrosis.

Primary outcome measures: Admission to an intensive care unit, a prolonged ( $>3$ days) hospital stay, receipt of mechanical ventilation and death in hospital. Logistic regression was used to calculate adjusted $\mathrm{OR}$ and $95 \% \mathrm{Cl}$ for these four outcomes.

Results: 30390 patients with allergic conditions were identified, of whom 2410 had anaphylaxis. The following results pertain to the subcohort of patients with anaphylaxis. Median age was 50 years (range 0-95 years) and $1470(61 \%)$ were female. The hospital mortality was $2.7 \%$. Although asthma was not associated with hospital mortality $(\mathrm{OR}=1.27,95 \% \mathrm{Cl}$ 0.55 to 2.90), asthmatics had more than twice the odds of non-asthmatics of receiving mechanical ventilation (OR=2.45, $95 \% \mathrm{Cl} 1.81$ to 3.33). Chronic bronchitis, COPD, emphysema and interstitial lung diseases (ILDs) were also associated with an increased risk of requiring mechanical ventilation. Chronic bronchitis and COPD were associated with a prolonged length of stay: $\mathrm{OR}=2.69(95 \% \mathrm{Cl} 1.45$ to 4.98$)$ and $\mathrm{OR}=1.86(95 \%$ $\mathrm{Cl} 1.30$ to 2.66 ), respectively. ILD was the only chronic pulmonary disease associated with an elevated risk of hospital mortality: OR=8.71 (95\% $\mathrm{Cl} 1.48$ to 51.20$)$.

Conclusions: In this unique analysis of a large database, we found that asthma, COPD and other chronic pulmonary diseases increased the risk of adverse outcomes among hospitalised patients with anaphylaxis.

\section{ARTICLE SUMMARY}

Article focus

- The association between chronic pulmonary diseases and indicators of anaphylaxis severity in hospitalised patients.

Key message

- Asthma, chronic obstructive pulmonary disease, and other chronic pulmonary diseases increase the risk of adverse outcomes among hospitalised patients with anaphylaxis.

Strengths and limitations of this study

- The authors did not have access to the complete medical records of the patients. Additionally, there are no published findings that summarise the sensitivity and positive predictive value of the International Classification of Diseases, Ninth Revision, Clinical Modification coding of all-cause anaphylaxis in hospital inpatient databases.

\section{INTRODUCTION}

Anaphylaxis is a serious allergic reaction that is rapid in onset and potentially fatal. ${ }^{1}$ It is usually triggered through an IgE-dependent immunological mechanism by exposure to a food, medication, stinging insect venom, natural rubber latex or other allergen to which the patient is sensitised. ${ }^{12}$ Diagnosis of an anaphylactic episode involves validated and defined clinical criteria ${ }^{134}$ and is based on a sudden onset of symptoms, typically in two or more body systems, within minutes to hours after exposure to a trigger. ${ }^{1}$ There is no rapid laboratory test to confirm the diagnosis at the time of presentation. ${ }^{25}$ The symptoms and signs of anaphylaxis are underrecognised by patients and/or caregivers, and are underdiagnosed by healthcare professionals. ${ }^{6}$ The lifetime prevalence of anaphylaxis has been estimated to be $0.05-2 \%{ }^{7}$ 
Some patients are potentially at increased risk of severe or fatal anaphylaxis because of age (eg, the elderly), ${ }^{8}$ or concomitant diseases such as mastocytosis/clonal mast cell disorders ${ }^{9-14}$ and asthma. ${ }^{15-23}$ They might also be at increased risk if they are concurrently taking medications such as a $\beta$-adrenergic blocker, an ACE inhibitor or indeed any antihypertensive medication, ${ }^{24}$ or if they have elevated baseline levels of mediators involved in the anaphylaxis pathogenesis, for example, histamine, tryptase, bradykinin or platelet-activating factor. ${ }^{2} 8$

For asthma, the association with an increased risk of severe or fatal anaphylaxis is strongly supported by death and autopsy studies published at intervals during the past 24 years, ${ }^{15-23}$ and by two epidemiology studies published in 2010 that examined the association between asthma and the risk of anaphylaxis in large populations. ${ }^{25}{ }^{26}$ Using a general practitioner database from the UK, Gonzalez-Perez et a $t^{25}$ identified a sample of 177000 asthmatics and 200000 non-asthmatics, ranging in age from 10 to 79 years, and reported that the patients with asthma had a greater risk of anaphylaxis than those without asthma, and that the risk was greater in severe asthma than in non-severe asthma. Iribarren $e t a l^{26}$ assembled a cohort of 1052812 members of Kaiser Permanente of Northern California, half $(n=526406)$ of whom had asthma. These investigators found that asthmatics had an increased risk of anaphylactic shock and other allergy diagnoses compared with members who did not have asthma.

For chronic obstructive pulmonary disease (COPD), the relationship with an increased risk of severe or fatal anaphylaxis is until now based primarily on two autopsy studies. In one of these studies, 5/25 adults aged 5871 years dying from anaphylaxis had comorbid COPD, and in the other study, 2/28 adults dying from anaphylaxis had comorbid COPD. ${ }^{22} 23$

For other chronic pulmonary diseases such as bronchiectasis, chronic bronchitis, cystic fibrosis, emphysema, hypersensitivity pneumonitis, interstitial lung diseases and pulmonary eosinophilia disorders, including allergic bronchopulmonary aspergillosis and Churg-Strauss disease, the association, if any, with an increased risk of severe or fatal anaphylaxis remains to be defined.

Additional population-based epidemiological studies are therefore needed to explore the relationship of asthma severity with anaphylaxis and to investigate the epidemiology of comorbid COPD and other respiratory disorders with anaphylaxis.

We hypothesised that among hospitalised patients with allergic conditions including anaphylaxis, chronic comorbid respiratory disease might affect the severity of the allergic condition adversely, as reflected in various outcomes, including the length of hospital inpatient stay. We tested this hypothesis using a large state-wide hospital database.

\section{METHODS}

The study protocol was reviewed by the Institutional Review Board (IRB) for the Protection of Human
Subjects of Texas Tech University Health Sciences Center, El Paso, Texas, and was deemed to be exempt from formal IRB review. The protocol was approved by the Texas Department of State Health Services IRB \#1, Austin, Texas.

\section{Source population and inclusion criteria}

A retrospective cohort study was performed using hospital inpatient discharge data that are being leased by the Department of Obstetrics and Gynecology from the Texas Department of State Health Services (Austin, Texas). Public use as well as research data were used in this study. These data are from all state licensed hospitals except those that are exempt from reporting to the Texas Health Care Information Council. According to the data user manual, "Exempt hospitals include those located in a county with a population of less than 35000 , or those located in a county with a population more than 35000 and with fewer than 100 licensed hospital beds and not located in an area that is delineated as an urbanized area by the United States Bureau of the Census..." Hospitals that do not seek insurance payment or government reimbursement are also exempt from the reporting requirement. In 2007, quarterly figures indicated that, on average, $80 \%$ of the state licensed hospitals in Texas were required to report their data to the Texas Health Care Information Collection, and of this group, $99 \%$ did do so (Personal communication, Texas Health Care Information Collection staff).

A unique patient identifier was available in the research portion of the database. This variable can identify patients who had repeated hospitalisations at reporting facilities during the study period or were transferred to another facility. If multiple discharge records existed for a single individual, then only the first medical record was used in our analyses.

The electronic hospital discharge dataset contains clinical and demographic information for millions of individuals who were discharged from reporting hospitals throughout Texas during the calendar-years 2004, 2005, 2006 and 2007. The principal discharge diagnosis and up to 24 secondary diagnoses were evaluated. Each record also contained up to a maximum of 25 procedures (a principal procedure and up to 24 secondary procedures) that were performed during that particular hospital stay. The discharge diagnosis and procedure variables were coded using the International Classification of Diseases, Ninth Revision, Clinical Modification (ICD-9-CM).

Cases were included in our study if any of the following ICD-9-CM codes were found in any of the discharge diagnosis fields: 995 (other anaphylactic shock-allergic shock/anaphylactic reaction/anaphylaxis which was not otherwise specified or due to the adverse effect of a correct medicinal substance that was administered properly), codes 995.60 through 995.69 (anaphylactic shock due to an adverse food reaction such as peanuts or crustaceans), 995.4 (shock caused by anaesthesia) or 999.4 (anaphylactic shock caused by the serum). 
In addition to the above codes, which are specific for anaphylaxis, we also included the records of patients whose discharge diagnosis fields contained codes that are not specific for anaphylaxis, including 989.5 (toxic effect of venom), 708 (allergic urticaria), 708.9 (urticaria unspecified), 995.1 (angioneurotic oedema) and 995.3 (allergy unspecified). ICD-9-CM code 989.5 is frequently used to indicate allergic reactions to insect stings from Hymenoptera species, ${ }^{27}$ and was used in our previous epidemiological investigation of hospitalisations for anaphylaxis. ${ }^{28}$ Additional codes used by other investigators including 693.1 (dermatitis due to food), 988 (toxic effect of noxious substances eaten as food), 999.5 (other serum reaction) and 995.2 (adverse effect to correct medicinal substance properly administered/allergic reaction to correct medicinal substance properly administered/hypersensitivity to correct medicinal substance properly administered) were also included in our search strategy. ${ }^{29}$

Patients who had any of the allergic conditions listed above comprised the entire cohort. Patients who had a principal or secondary discharge diagnosis of anaphylaxis (defined as ICD-9-CM codes 995.0, 995.4, 995.60995.69 or 999.4) formed a subgroup of the overall cohort.

\section{Definition of exposure variables}

The pulmonary diseases listed in table 1 , for example, asthma, COPD and emphysema, were the main independent variables of interest. ${ }^{30}$ For each electronic patient record, all the diagnosis fields were searched for the ICD-9-CM codes listed in table 1. For example, if a code beginning with the numbers '493' was found in any of the discharge diagnosis fields, then the patient was considered to be an asthmatic.

\section{Table 1 Definition of comorbidities}

\begin{tabular}{ll}
\hline Comorbidity & ICD-9-CM code(s) \\
\hline $\begin{array}{l}\text { Allergic bronchopulmonary } \\
\text { aspergillosis }\end{array}$ & 518.6 \\
$\begin{array}{l}\text { Asthma (includes extrinsic } \\
\text { asthma, intrinsic asthma and }\end{array}$ & 493 \\
asthma with COPD) & \\
Bronchiectasis & 494 \\
Chronic bronchitis & 491 \\
Churg-Strauss disease & 446.4 \\
(Wegener's granulomatosis) & \\
COPD & 496 \\
Cystic fibrosis & 277.0 \\
Emphysema & 492 \\
Hypersensitivity pneumonitis & 495.9 \\
Interstitial lung diseases & $506.4,508.1,515$, \\
& $516.3,714.81,770.7$ \\
Pulmonary eosinophilia & 518.3 \\
\hline COPD, chronic obstructive pulmonary disease; ICD-9-CM, \\
International Classification of Diseases, Ninth Revision, Clinical \\
Modification.
\end{tabular}

\section{Definition of outcomes}

Four binary (dichotomous) outcomes were assessed in separate regression models: intensive/critical care unit (ICU) admission (yes/no), receipt of mechanical ventilation (yes/no), hospital mortality and a prolonged length of stay (defined as a stay longer than 3 days). Patients who were admitted to an ICU were identified using the ICU charges variable. Mechanical ventilation was defined as the presence of ICD-9-CM codes 96.70 (continuous mechanical ventilation of unspecified duration), 96.71 (continuous mechanical ventilation for less than 96 consecutive hours) or 96.72 (continuous mechanical ventilation for 96 consecutive hours or more) in any of the 25 procedure fields.

\section{Statistical analysis}

Data were managed and analysed using the SAS software V.9.2 (SAS Institute, Inc, Cary, North Carolina, USA). Initially, the GENMOD procedure was used to calculate risk ratios for the outcomes using log-binomial regression models. ${ }^{31}$ However, several of these models failed to converge, and hence the LOGISTIC procedure was used to calculate OR.

The following variables were considered confounders of the associations under study: patient age, race and Hispanic ethnicity, sex, health insurance status, ischaemic heart disease, chronic kidney disease and diabetes. Age in years was entered as a categorical variable using five indicator (dummy) variables to represent the following six age groups: $0-19,20-49,50-64,65-74,75-84$ and $\geq 85$ (referent). A combined race-ethnicity variable was created using the separate race and Hispanic ethnicity variables found in the hospital discharge dataset: White Hispanic, Black Non-Hispanic, Asian, Other and White Non-Hispanic (referent). Four indicator variables were entered into the regression models for race and ethnicity. The original health insurance variable had 23 possible responses. It was converted to a four-level variable: Uninsured, Medicaid, Medicare and Other (which includes Blue Cross/Blue Shield). The Uninsured category was created by combining the response 'self-pay' with the response 'charity, indigent or unknown'. The Other group served as the referent (comparison) group. Three indicator variables representing the new health insurance variable were entered in our models. Ischaemic heart disease was defined as the presence of ICD-9-CM codes 410 through 414 in any of the discharge diagnosis fields while chronic kidney disease and diabetes were defined as codes 585 and 250, respectively.

The number of in-hospital deaths in the subcohort of patients with anaphylaxis was small relative to the number of independent variables entered in each logistic regression model; specifically, there were fewer than 10 events per independent variable. ${ }^{32} 33$ All our models included 27 independent variables: the 11 concomitant chronic pulmonary diseases, 5 indicator variables for age, 4 indicator variables for race, 3 indicator variables for health insurance, patient sex and 3 dichotomous 
(present vs absent) chronic disease variables (one each for ischaemic heart disease, chronic kidney disease and diabetes). We attempted to use Firth's penalised maximum likelihood estimation to address this situation of too few events (deaths) relative to the number of independent variables. ${ }^{34}$ Two logistic regression models were created. One was a traditional model while the other used Firth's likelihood penalty to account for any bias caused by sparse data; however, the convergence of the model where Firth's bias correction was applied was questionable, and hence adjusted ORs for hospital mortality were reported from the traditional logistic model.

Adjusted ORs are reported along with 95\% CI. The OR was considered to be statistically significant if the CI excluded the null value one.

\section{RESULTS}

Overall, the cohort contained 30390 patients, of whom $2410(7.9 \%)$ had a principal or secondary discharge diagnosis of anaphylaxis (table 2). The median ages of the entire cohort and the subcohort of patients with anaphylaxis were 52 and 50 years, respectively. Sixty-one per cent of the patients who experienced anaphylaxis were female. Asthma and COPD were the most common chronic pulmonary conditions in both the full cohort and the subcohort of patients with anaphylaxis. Admission into the ICU and receipt of mechanical ventilation were more frequent in the anaphylaxis subcohort than in the full cohort.

ORs for four hospital outcomes in the whole cohort are shown in table 3. The risk factor of interest was a concomitant chronic pulmonary disease. Patients with pulmonary eosinophilia were almost four times as likely as patients without this condition to be admitted to the ICU $(\mathrm{OR}=3.89)$. This result was statistically significant at the 0.05 level: $1.86-8.14$. Significant positive relationships were found between hospital mortality and chronic bronchitis, emphysema and interstitial lung diseases. An inverse association appeared to be present between asthma and hospital mortality, with asthmatics experiencing a $38 \%$ reduction in the odds of dying in the hospital compared with non-asthmatics; however, this result was not statistically significant because the 95\% CI encompassed the null value of 1 ( $\mathrm{OR}=0.62,95 \%$ CI 0.38 to $1.00, \mathrm{p}=0.051)$. Seven pulmonary conditions were associated with elevated odds of a prolonged length of stay. Asthmatics were $67 \%$ more likely than nonasthmatics to receive mechanical ventilation $(\mathrm{OR}=1.67$, $95 \%$ CI 1.40 to 2.01). Several ORs could not be estimated due to the small number of patients with those specific pulmonary diseases. No associations were detected between seven of the pulmonary diseases, including asthma, and the outcome of admission to the ICU.

Adjusted ORs for four hospital outcomes in the subcohort of patients who had anaphylaxis are reported in table 4. Asthmatics did not have an elevated risk of being admitted to the ICU, yet they had more than a doubling of their odds of receiving mechanical ventilation compared with non-asthmatics $(\mathrm{OR}=2.45)$. In the anaphylaxis subcohort, the presence of COPD influenced the risk of a prolonged length of stay $(\mathrm{OR}=1.86$, $95 \%$ CI 1.30 to 2.66) but did not impact the odds of being admitted to an ICU or hospital mortality. In the anaphylaxis cohort, statistically significant associations were noted between interstitial lung diseases and two outcomes: hospital mortality $(\mathrm{OR}=8.71)$, and receipt of mechanical ventilation $(\mathrm{OR}=5.16)$. ORs could not be estimated for allergic bronchopulmonary aspergillosis, Churg-Strauss disease and hypersensitivity pneumonitis due to the rarity of these diseases (only one patient in the anaphylaxis cohort had allergic bronchopulmonary aspergillosis and none in this cohort had Churg-Strauss disease or hypersensitivity pneumonitis). Mastocytosis (ICD-9-CM code 202.6) was not included in any of our models because only 5 of the 30390 patients in the full cohort had this discharge diagnosis, 3 of whom also had anaphylaxis (data not shown).

\section{DISCUSSION}

Large population-based studies of the effect of chronic pulmonary diseases on the outcomes of hospitalised patients with anaphylaxis are lacking. We report the association between several concomitant pulmonary diseases and four indicators of anaphylaxis severity in hospitalised patients with anaphylaxis in Texas, a state with a large population (estimated at 22778123 in 2005). ${ }^{35}$

We found that asthmatics were $28 \%$ less likely to have a prolonged length of stay $(\mathrm{OR}=0.72,95 \%$ CI 0.55 to $0.95)$ and more than twice as likely to be placed on a ventilator $(\mathrm{OR}=2.16,95 \%$ CI 1.60 to 2.91$)$ than nonasthmatics. Similar findings were reported from a smaller study that we conducted previously using data from Florida. ${ }^{28}$ In the latter study, investigators analysed the records of 464 hospitalised patients with anaphylaxis and found that asthmatics had a length of stay that was, on average, 2.15 days shorter than that of non-asthmatics $(p=0.04)$. This reduction could possibly be due to hospitals adopting asthma care maps or clinical pathways in the past decade. Asthmatics in the Florida study were also at a higher risk of receiving mechanical ventilation compared with non-asthmatics: adjusted relative risk $=2.72,95 \%$ CI 1.07 to $6.91, \mathrm{p}=0.04$ ).

Limitations of this state-wide administrative hospital discharge database include $80 \%$ rather than $100 \%$ coverage of state licensed hospitals, lack of access to emergency department data, and lack of detailed information about diagnosis and treatment as documented in the complete medical records of these patients. Our data use agreement with the Texas Department of State Health Services stipulates, "The licensee will not attempt to link nor permit others to attempt to link the hospital stay records of patients in this data set with personally identifiable records from any other source." 
Table 2 Demographic and clinical characteristics of 30390 patients with selected allergic conditions who were hospitalised throughout Texas and discharged between 2004 and 2007

\begin{tabular}{|c|c|c|}
\hline Characteristic & $\begin{array}{l}\text { Entire cohort } \\
\mathrm{N}=30390 \\
\text { Number }(\%)\end{array}$ & $\begin{array}{l}\text { Patients with anaphylaxis } \\
\mathrm{N}=2410 \\
\text { Number (\%) }\end{array}$ \\
\hline \multicolumn{3}{|l|}{ Age (years) ${ }^{\star}$} \\
\hline $0-19$ & $4176(13.7)$ & $311(12.9)$ \\
\hline 20-49 & $9640(31.7)$ & $886(36.8)$ \\
\hline $50-64$ & $6415(21.1)$ & $654(27.1)$ \\
\hline $65-74$ & 4025 (13.2) & $298(12.4)$ \\
\hline $75-84$ & $4072(13.4)$ & $196(8.1)$ \\
\hline$\geq 85$ & $2062(6.8)$ & $65(2.7)$ \\
\hline \multicolumn{3}{|l|}{ Race and ethnicity } \\
\hline Asian or Pacific Islander & $461(1.5)$ & $43(1.8)$ \\
\hline Black non-Hispanic & $4254(14.0)$ & $312(13.0)$ \\
\hline Other & 5217 (17.2) & $425(17.6)$ \\
\hline White Hispanic & $2588(8.5)$ & $242(10.0)$ \\
\hline White non-Hispanic & $17870(58.8)$ & $1388(57.6)$ \\
\hline Female sex & $17324(57.0)$ & $1470(61.0)$ \\
\hline \multicolumn{3}{|l|}{ Health insurance status } \\
\hline Medicaid & 3725 (12.3) & $253(10.5)$ \\
\hline Medicare & $10993(36.2)$ & $621(25.8)$ \\
\hline Uninsured, self-pay, charity & 3622 (11.9) & $332(13.8)$ \\
\hline Other (including commercial insurance) & $12050(39.7)$ & $1204(50.0)$ \\
\hline \multicolumn{3}{|l|}{ Allergic conditions } \\
\hline Allergy unspecified & $4435(14.6)$ & $10(0.4)$ \\
\hline Anaphylaxis & $2410(7.9)$ & $2410(100)$ \\
\hline Angioneurotic oedema & $4482(14.8)$ & $174(7.2)$ \\
\hline Dermatitis due to food taken internally & $297(1.0)$ & $14(0.6)$ \\
\hline $\begin{array}{l}\text { Other and unspecified adverse effect of drug, medicinal and biological } \\
\text { substance }\end{array}$ & $7138(23.5)$ & $3(0.1)$ \\
\hline Other serum reaction not elsewhere classified & $320(1.1)$ & $1(0.04)$ \\
\hline Toxic effect of noxious substances eaten as food & $172(0.6)$ & $1(0.04)$ \\
\hline Toxic effect of venom & $6430(21.2)$ & $19(0.8)$ \\
\hline \multicolumn{3}{|l|}{ Urticaria } \\
\hline Allergic urticaria & 3091 (10.2) & $115(4.8)$ \\
\hline Unspecified urticaria & $2455(8.1)$ & $38(1.6)$ \\
\hline \multicolumn{3}{|l|}{ Pulmonary conditions } \\
\hline Allergic bronchopulmonary aspergillosis & $3(0.0)$ & $1(0.04)$ \\
\hline $\begin{array}{l}\text { Asthma (includes extrinsic asthma, intrinsic asthma and asthma with } \\
\text { chronic obstructive pulmonary disease) }\end{array}$ & $2772(9.1)$ & $334(13.9)$ \\
\hline Bronchiectasis & $61(0.2)$ & $4(0.2)$ \\
\hline Chronic bronchitis & $845(2.8)$ & $49(2.0)$ \\
\hline Churg-Strauss disease (Wegener's granulomatosis) & $3(0.0)$ & $0(0)$ \\
\hline Chronic obstructive pulmonary disease & $1818(6.0)$ & $149(6.2)$ \\
\hline Cystic fibrosis & $21(0.1)$ & $4(0.2)$ \\
\hline Emphysema & $159(0.5)$ & $9(0.4)$ \\
\hline Hypersensitivity pneumonitis & $3(0.0)$ & $0(0.0)$ \\
\hline Interstitial lung diseases & $200(0.7)$ & $10(0.4)$ \\
\hline Pulmonary eosinophilia & $32(0.1)$ & $6(0.3)$ \\
\hline \multicolumn{3}{|l|}{ Other selected comorbidities } \\
\hline Chronic kidney disease & $1280(4.2)$ & $95(3.9)$ \\
\hline Diabetes & $5539(18.2)$ & $426(17.7)$ \\
\hline Ischaemic heart disease & $7108(23.4)$ & $447(18.6)$ \\
\hline \multicolumn{3}{|l|}{ Hospital outcomes } \\
\hline Admitted to an intensive care unit & $9343(30.7)$ & $1401(58.1)$ \\
\hline Died & $452(1.5)$ & $64(2.7)$ \\
\hline Prolonged length of stay (defined as a stay $>3$ days $\dagger$ ) & $13511(44.5)$ & $797(33.1)$ \\
\hline Received mechanical ventilation & $1181(3.9)$ & $365(15.2)$ \\
\hline
\end{tabular}


Table 3 Association between pulmonary diseases and four hospital outcomes in 30390 patients with allergic conditions ${ }^{\star}$

\begin{tabular}{|c|c|c|c|c|c|c|c|c|}
\hline \multirow[b]{2}{*}{ Pulmonary disease (present vs absent) } & \multicolumn{2}{|c|}{$\begin{array}{l}\text { Admitted to intensive } \\
\text { care unit }\end{array}$} & \multicolumn{2}{|c|}{ Hospital mortality } & \multicolumn{2}{|c|}{$\begin{array}{l}\text { Prolonged length of } \\
\text { stayt }\end{array}$} & \multicolumn{2}{|c|}{$\begin{array}{l}\text { Receipt of } \\
\text { mechanical } \\
\text { ventilation }\end{array}$} \\
\hline & $\overline{\mathrm{OR}}$ & $95 \% \mathrm{Cl}$ & $\overline{\text { OR }}$ & $95 \% \mathrm{Cl}$ & $\overline{\text { OR }}$ & $95 \% \mathrm{Cl}$ & $\overline{\text { OR }}$ & $95 \% \mathrm{Cl}$ \\
\hline Allergic bronchopulmonary aspergillosis & 4.53 & 0.41 to 50.47 & $\ddagger$ & $\ddagger$ & $\ddagger$ & $\ddagger$ & $\ddagger$ & $\ddagger$ \\
\hline Asthma & 1.08 & 0.99 to 1.18 & 0.62 & 0.38 to 1.00 & 1.03 & 0.95 to 1.12 & 1.67 & 1.40 to 2.01 \\
\hline Bronchiectasis & 1.02 & 0.58 to 1.79 & 1.22 & 0.28 to 5.40 & 3.90 & 1.98 to 7.68 & 0.89 & 0.21 to 3.73 \\
\hline Chronic bronchitis & 1.11 & 0.96 to 1.29 & 1.90 & 1.35 to 2.68 & 1.95 & 1.67 to 2.27 & 1.79 & 1.34 to 2.37 \\
\hline Churg-Strauss disease (Wegener's granulomatosis) & 1.10 & 0.10 to 12.28 & $\ddagger$ & $\ddagger$ & 0.71 & 0.06 to 8.36 & $\ddagger$ & $\ddagger$ \\
\hline Chronic obstructive pulmonary disease & 1.35 & 1.22 to 1.50 & 1.12 & 0.83 to 1.50 & 1.41 & 1.28 to 1.57 & 1.98 & 1.62 to 2.41 \\
\hline Cystic fibrosis & 0.59 & 0.17 to 2.07 & $\ddagger$ & $\ddagger$ & 5.74 & 1.85 to 17.84 & $\ddagger$ & $\ddagger$ \\
\hline Emphysema & 1.49 & 1.08 to 2.05 & 3.04 & 1.56 to 5.93 & 1.42 & 1.03 to 1.97 & 2.14 & 1.20 to 3.81 \\
\hline Hypersensitivity pneumonitis & 0.67 & 0.06 to 7.55 & $\ddagger$ & $\ddagger$ & 2.00 & 0.17 to 23.53 & $\ddagger$ & $\ddagger$ \\
\hline Interstitial lung diseases & 1.61 & 1.21 to 2.14 & 2.69 & 1.53 to 4.73 & 1.93 & 1.40 to 2.65 & 1.22 & 0.67 to 2.21 \\
\hline Pulmonary eosinophilia & 3.89 & 1.86 to 8.14 & 1.70 & 0.22 to 12.98 & 3.97 & 1.68 to 9.37 & 2.73 & 0.94 to 7.91 \\
\hline
\end{tabular}

Adjusted $\mathrm{OR}$ and $\mathrm{Cl}$ were calculated from logistic regression models.

*Each OR was adjusted for the remaining pulmonary conditions, age, race-ethnicity, sex, health insurance status, chronic kidney disease, diabetes, and ischaemic heart disease.

†Defined as a length of stay longer than 3 days.

¥Could not be estimated.

Table 4 Association between pulmonary diseases and four hospital outcomes in 2410 patients with anaphylaxis*

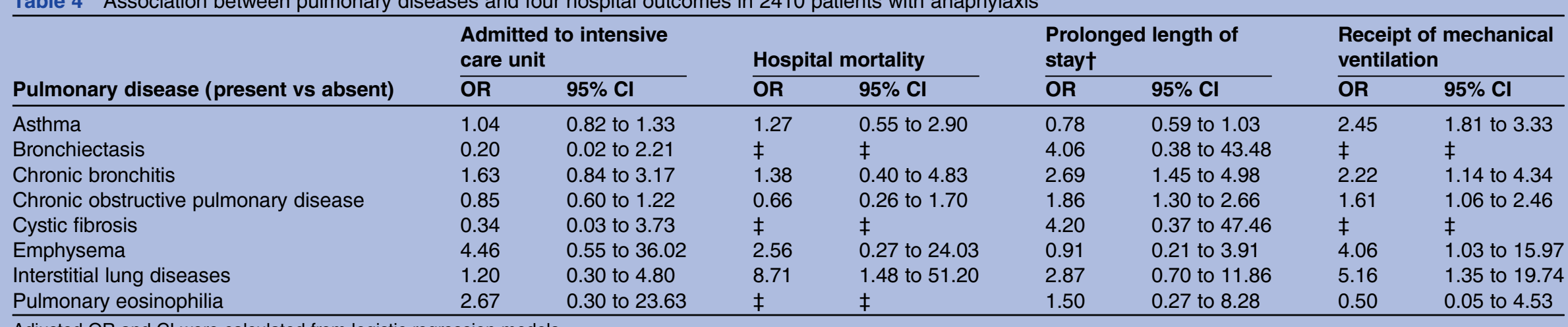

Adjusted $\mathrm{OR}$ and $\mathrm{Cl}$ were calculated from logistic regression models.

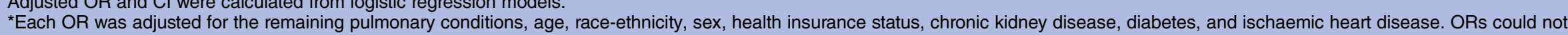
be estimated for the following outcomes: allergic bronchopulmonary aspergillosis, Churg-Strauss disease and hypersensitivity pneumonitis.

†Defined as a length of stay longer than 3 days.

¥Could not be estimated. 
A general limitation of using state and federal administrative hospital discharge databases is the potential misclassification of both diagnoses and procedures which are typically coded using ICD-9-CM. While the accuracy of the ICD-9-CM coding of various diseases and syndromes, such as breast cancer, acute myocardial infarction and preeclampsia, in hospital claims data has been reported, ${ }^{36}{ }^{37}$ to our knowledge there are no published findings which summarise both the sensitivity and positive predictive value of the ICD-9-CM coding of all-cause anaphylaxis in the records of children and adults found in hospital inpatient databases. ${ }^{38}$ Clark et $a l^{27}$ investigated the ICD-9-CM coding of emergency department visits for food and insect sting allergy. Similar investigations of anaphylaxis coding found in hospital inpatient discharge datasets would be welcome.

In summary, in this unique exploratory analysis of a large database, we examined the association between chronic pulmonary diseases and four indicators of anaphylaxis severity in hospitalised patients. We found that asthma, COPD and other chronic pulmonary diseases increased the risk of adverse outcomes among hospitalised patients with anaphylaxis.

Acknowledgements The abstract of this paper was presented at the 2012 Annual Meeting of the American Academy of Allergy, Asthma and Immunology on 5 March 2012, in Orlando, Florida. The authors thank Javier Palomino, MS, and Leticia M Perez, for their data management services. The authors also acknowledge the use of the Texas Hospital Inpatient Discharge Public Use (and Research Use) Data File, quarters 1 through 4, for the years 2004 through 2007, Texas Department of State Health Services, Center for Health Statistics-Texas Health Care Information Collection (THCIC), Austin, Texas, USA.

Contributors FERS helped to interpret the literature, conceive the hypothesis, review the data and write the manuscript. ZDM helped to interpret the literature and conceive the hypothesis. He identified the database, wrote the SAS computer code to analyse the data, reviewed the data and drafted the manuscript. Both authors approved the final version of the manuscript. ZDM is the guarantor.

Funding The study was supported by the Department of Obstetrics and Gynecology, Paul L Foster School of Medicine, Texas Tech University Health Sciences Center, El Paso, Texas, and the Department of Pediatrics and Child Health, Faculty of Medicine, University of Manitoba.

Competing interests None.

Ethics approval Institutional Review Board for the Protection of Human Subjects, Texas Tech University Health Sciences Center, El Paso, Texas, USA.

Provenance and peer review Not commissioned; externally peer reviewed.

Data sharing statement The data user agreement limits the sharing of the Public Use Data File to investigators at the Texas Tech University Health Sciences Center, El Paso, Texas, USA.

Open Access This is an Open Access article distributed in accordance with the Creative Commons Attribution Non Commercial (CC BY-NC 3.0) license, which permits others to distribute, remix, adapt, build upon this work noncommercially, and license their derivative works on different terms, provided the original work is properly cited and the use is non-commercial. See: http:// creativecommons.org/licenses/by-nc/3.0/

\section{REFERENCES}

1. Sampson HA, Munoz-Furlong A, Campbell RL, et al. Second symposium on the definition and management of anaphylaxis: summary report-Second National Institute of Allergy and Infectious
Disease/Food Allergy and Anaphylaxis Network symposium. $J$ Allergy Clin Immunol 2006;117:391-7.

2. Simons FER. Anaphylaxis. J Allergy Clin Immunol 2010;125:S161-81.

3. Harduar-Morano L, Simon MR, Watkins S, et al. Algorithm for the diagnosis of anaphylaxis and its validation using population-based data on emergency department visits for anaphylaxis in Florida. J Allergy Clin Immunol 2010;126:98-104.

4. Campbell RL, Hagan JB, Manivannan V, et al. Evaluation of National Institute of Allergy and Infectious Diseases/Food Allergy and Anaphylaxis Network criteria for the diagnosis of anaphylaxis in emergency department patients. J Allergy Clin Immunol 2012;129:748-52.

5. Simons FE, Frew AJ, Ansotegui IJ, et al. Risk assessment in anaphylaxis: current and future approaches. J Allergy Clin Immunol 2007;120:S2-24.

6. Simons FER, Sampson HA. Anaphylaxis epidemic: fact or fiction? J Allergy Clin Immunol 2008;122:1166-8.

7. Lieberman P, Camargo CA Jr, Bohlke K, et al. Epidemiology of anaphylaxis: findings of the American College of Allergy, Asthma and Immunology Epidemiology of Anaphylaxis Working Group. Ann Allergy Asthma Immunol 2006;97:596-602.

8. Simons FER, Ardusso LRF, Bilo MB, et al. World Allergy Organization anaphylaxis guidelines: summary. J Allergy Clin Immunol 2011;127:587-93.e22.

9. Brockow $\mathrm{K}$, Jofer $\mathrm{C}$, Behrendt $\mathrm{H}$, et al. Anaphylaxis in patients with mastocytosis: a study on history, clinical features and risk factors in 120 patients. Allergy 2008;63:226-32.

10. Muller UR. Elevated baseline serum tryptase, mastocytosis and anaphylaxis. Clin Exp Allergy 2009;39:620-2.

11. Metcalfe DD, Schwartz LB. Assessing anaphylactic risk? Consider mast cell clonality. J Allergy Clin Immunol 2009;123:687-8.

12. Rueff F, Przybilla B, Bilo MB, et al. Predictors of severe systemic anaphylactic reactions in patients with Hymenoptera venom allergy: importance of baseline serum tryptase-a study of the European Academy of Allergology and Clinical Immunology Interest Group on Insect Venom Hypersensitivity. J Allergy Clin Immunol 2009;124:1047-54.

13. Bonadonna P, Perbellini O, Passalacqua G, et al. Clonal mast cell disorders in patients with systemic reactions to Hymenoptera stings and increased serum tryptase levels. J Allergy Clin Immunol 2009;123:680-6.

14. Alvarez-Twose I, Gonzalez de Olano D, Sanchez-Munoz L, et al. Clinical, biological, and molecular characteristics of clonal mast cell disorders presenting with systemic mast cell activation symptoms. $J$ Allergy Clin Immunol 2010;125:1269-78.

15. Yunginger JW, Sweeney KG, Sturner WQ, et al. Fatal food-induced anaphylaxis. JAMA 1988;260:1450-2.

16. Sampson HA, Mendelson L, Rosen JP. Fatal and near-fatal anaphylactic reactions to food in children and adolescents. $N$ Engl $J$ Med 1992;327:380-4.

17. Pumphrey RSH. Lessons for management of anaphylaxis from a study of fatal reactions. Clin Exp Allergy 2000;30:1144-50.

18. Pumphrey RSH, Roberts ISD. Postmortem findings after fatal anaphylactic reactions. J Clin Pathol 2000;53:273-6.

19. Bock SA, Munoz-Furlong A, Sampson HA. Fatalities due to anaphylactic reactions to foods. J Allergy Clin Immunol 2001:107:191-3.

20. Bock SA, Munoz-Furlong A, Sampson HA. Further fatalities caused by anaphylactic reactions to food, 2001-2006. J Allergy Clin Immunol 2007:119:1016-18.

21. Pumphrey RSH, Gowland MH. Further fatal allergic reactions to food in the United Kingdom, 1999-2006. J Allergy Clin Immunol 2007:119:1018-19.

22. Greenberger PA, Rotskoff BD, Lifschultz B. Fatal anaphylaxis: postmortem findings and associated comorbid diseases. Ann Allergy Asthma Immunol 2007:98:252-7.

23. Shen Y, Li L, Grant J, et al. Anaphylactic deaths in Maryland (United States) and Shanghai (China): a review of forensic autopsy cases from 2004 to 2006. Forensic Sci Int 2009;186:1-5.

24. Lee S, Hess EP, Nestler DM, et al. Antihypertensive medication use is associated with increased organ system involvement and hospitalization in emergency department patients with anaphylaxis. $J$ Allergy Clin Immunol 2013;131:1103-8.

25. Gonzalez-Perez A, Aponte Z, Vidaurre CF, et al. Anaphylaxis epidemiology in patients with and patients without asthma: a United Kingdom database review. J Allergy Clin Immunol 2010;125:1098-104.

26. Iribarren C, Tolstykh IV, Miller MK, et al. Asthma and the prospective risk of anaphylactic shock and other allergy diagnoses in a large integrated health care delivery system. Ann Allergy Asthma Immunol 2010;104:371-7. 
27. Clark S, Gaeta TJ, Kamarthi GS, et al. ICD-9-CM coding of emergency department visits for food and insect sting allergy. Ann Epidemiol 2006;16:696-700.

28. Mulla ZD, Simon MR. Hospitalizations for anaphylaxis in Florida: epidemiologic analysis of a population-based dataset. Int Arch Allergy Immunol 2007;144:128-36.

29. Clark S, Camargo CA Jr. Epidemiology of anaphylaxis. Immunol Allergy Clin North Am 2007;27:145-63.

30. Longo DL, Fauci AS, Kasper DL, et al. eds. Harrison's principles of internal medicine. 18th edn. The McGraw-Hill Companies, Inc, 2012.

31. Robbins AS, Chao SY, Fonseca VP. What's the relative risk? A method to directly estimate risk ratios in cohort studies of common outcomes. Ann Epidemiol 2002;12:452-4.

32. Peduzzi P, Concato J, Kemper E, et al. A simulation study of the number of events per variable in logistic regression analysis. $J$ Clin Epidemiol 1996;49:1373-9.

33. Harrell FE Jr. Regression modeling strategies: with applications to linear models, logistic regression, and survival analysis. New York, NY: Springer, 2001:207-10.
34. Fernandez NP, Mulla ZD. Avoiding sparse data bias: an example from gynecologic oncology. J Registry Manag 2012;39:167-71.

35. United States Census Bureau. Intercensal Estimates of the Resident Population for the United States, Regions, States, and Puerto Rico, 2000 to July 1, 2010. http://www.census.gov/popest/ data/intercensal/state/tables/ST-ESTOOINT-01.xls (accessed 11 Dec 2011)

36. Fisher ES, Whaley FS, Krushat WM, et al. The accuracy of Medicare's hospital claims data: progress has been made, but problems remain. Am J Public Health 1992;82:243-8.

37. Yasmeen S, Romano PS, Schembri ME, et al. Accuracy of obstetric diagnoses and procedures in hospital discharge data. Am J Obstet Gynecol 2006;194:992-1001.

38. Schneider $\mathrm{G}$, Kachroo S, Jones N, et al. A systematic review of validated methods for identifying anaphylaxis, including anaphylactic shock and angioneurotic edema, using administrative and claims data. Pharmacoepidemiol Drug Saf 2012;21(Suppl 1): 240-7. 